\title{
Endoscopy after esophagectomy: Safety demonstrated in a porcine model
}

Vignesh Raman, MD, ${ }^{a}$ Karen L. Moodie, DVM, ${ }^{\mathrm{b}}$ Obinna O. Ofoche, BS, ${ }^{\mathrm{a}}$ Larry R. Kaiser, MD, FACS, ${ }^{\mathrm{c}, \mathrm{d}}$ and Cherie P. Erkmen, MD ${ }^{\mathrm{d}}$

\begin{abstract}
Background: Endoscopy is useful in assessing conduit ischemia and anastomotic leaks after esophagectomy but poses a theoretical threat of anastomotic disruption. We used a porcine model to evaluate the safety of endoscopy after esophagectomy.

Methods: We performed esophagectomies in 10 live pigs and performed endoscopy with progressive air insufflation and continuous intraluminal pressure monitoring. We stopped insufflation when the intraluminal pressure reached a plateau. We assessed the integrity of the conduit and anastomosis via endoscopy. We also performed pulse oximetry of the stomach and Doppler velocimetry of the right gastroepiploic artery on 5 live pigs to study the effects of endoscopic gastric insufflation.

Results: With gentle air insufflation, there was no measurable increase in intraluminal pressure, disruption of the conduit or anastomosis, or significant gastric distension. With progressive insufflation, the intraluminal pressure reached a plateau at a maximum of $8.7 \pm 2.1 \mathrm{~cm} \mathrm{H}_{2} \mathrm{O}(95 \%$ confidence interval, 7.210.2). At this plateau, air leaked retrograde via the mouth, which prevented further gastric distension. There were no significant changes in oxyhemoglobin saturation along various regions in the stomach even with maximal insufflation sustained for 10 minutes. There was a momentary reduction in gastroepiploic flow from $12.0 \pm 1.0[95 \%$ confidence interval, $10.8-13.2] \mathrm{mL} / \mathrm{min} / 100 \mathrm{~g}$ to $9.6 \pm 1.5$ [95\% confidence interval, $7.8-11.4] \mathrm{mL} / \mathrm{min} / 100 \mathrm{~g}$ immediately after maximal insufflation, but flow recovered to $11 \pm 1.3[9.6,12.8] \mathrm{mL} / \mathrm{min} / 100 \mathrm{~g}$ after $10 \mathrm{mi}-$ nutes of sustained insufflation.
\end{abstract}

Conclusions: Endoscopy after esophagectomy with gentle or maximal air insufflation results in safe endoluminal pressures and minimal disturbance of blood flow and oxygenation. (J Thorac Cardiovasc Surg 2017;154:1152-8)

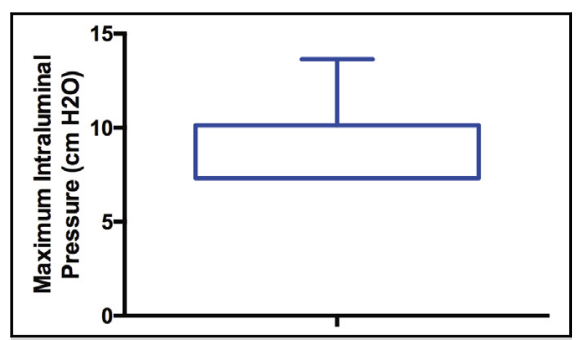

Endoscopy after esophagectomy exerts minimal intraluminal pressure in conduit.

\section{Central Message}

Endoscopy after esophagectomy with gentle or maximal air insufflation results in safe endoluminal pressures and minimal disturbance of blood flow and oxygenation.

\section{Perspective}

Endoscopy can be used to assess anastomoses and manage leaks complicating esophagectomy but poses a risk of anastomotic disruption. We used an in vivo porcine model to demonstrate that endoscopy after esophagectomy is likely safe. Our results form the basis for a clinical trial of endoscopy after esophagectomy and offer preliminary reassurance of its safety.

See Editorial Commentary pages 1159 and 1161.
Esophagectomy carries significant morbidity. Ischemia to the gastric conduit and anastomotic leaks both are

\footnotetext{
From the a Department of General Surgery, Duke University Medical Center, Durham, NC; bepartment of Surgery, Geisel School of Medicine at Dartmouth, Hanover, $\mathrm{NH}$; 'President and CEO, and ${ }^{\mathrm{d}}$ Department of Thoracic Medicine and Surgery, Temple University Health System, Philadelphia, Pa.

Funding was provided by a Dartmouth SYNERGY grant (Grant 30.169.287104. 59450).

Received for publication May 3, 2016; revisions received Nov 26, 2016; accepted for publication Dec 17, 2016; available ahead of print March 11, 2016.

Address for reprints: Cherie P. Erkmen, MD, Thoracic Medicine and Surgery, Temple University Health System, 3401 North Broad St C-100, Philadelphia, PA 19140 (E-mail: cherie.p.erkmen@tuhs.temple.edu).

0022-5223

Copyright (C) 2017 by The American Association for Thoracic Surgery. This is an open access article under the CC BY-NC-ND license (http://creativecommons.org/ licenses/by-nc-nd/4.0/).

http://dx.doi.org/10.1016/j.jtcvs.2016.12.053
}

potentially fatal complications occurring in approximately $10 \%$ of the postesophagectomy population. ${ }^{1}$ Contrast esophagograms can be unreliable in the detection of anastomotic leaks, with a reported sensitivity between $40 \%$ and $66 \%{ }^{2}$ Upper endoscopy can be a useful tool to identify and characterize leaks after esophagectomy. ${ }^{3-6}$ Endoscopy can differentiate leaks caused by technical mishaps from those caused by conduit ischemia. It also has the benefit of detecting and quantifying the viability of the gastric

Scanning this QR code will take you to the article title page. 
conduit, which can guide management. ${ }^{7}$ Endoscopy also can be used therapeutically to introduce stents into leaking anastomoses. ${ }^{8,9}$

Despite the benefits of endoscopy, clinicians remain reluctant to perform upper endoscopy after an esophagectomy because of the theoretical risk of disrupting the anastomosis. ${ }^{3,5,6,10,11}$ Endoscopy carries potential risks: (1) the endoscope could mechanically disrupt the anastomosis, (2) insufflation pressure during endoscopy could perforate the anastomosis, and (3) insufflation can cause gastric conduit distension, compromising blood flow and conduit perfusion. Based on our previous studies measuring intraluminal pressure thresholds of esophagogastric anastomoses, we hypothesized that pressures imparted during endoscopy would not disrupt an anastomosis. Furthermore, endoscopic pressures and manipulation would not significantly compromise regional blood flow or perfusion.

\section{METHODS}

\section{Esophagectomy, Endoscopy, and Pressure Measurements}

Our study was approved by our Institutional Animal Care and Use Committee (protocol erkm.cp.1). An esophagectomy was performed on 10 anesthetized pigs as described in our previous work. ${ }^{12}$ The esophagus was transected at a midthoracic location, the stomach was transected near the cardia, and a linear stapler (ETHICON ENDO-SURGERY Linear Cutter 75; Ethicon, Somerville, NJ) was used to create a side-to-side, functional end-to-end esophagogastric anastomosis. We use the same anastomotic technique in all our porcine studies that we use in patients, with a leak rate of approximately $12 \%$, comparable with other techniques, and the linear stapled technique is the most commonly used method today. ${ }^{13,14}$ The gastric conduit was tubularized by stapling the stomach along the lesser curvature to create a 4-cm wide tube (DST Series GIA $80 \mathrm{~mm}$; Covidien, Plymouth, Minn).

After the anastomosis, with the pig lying in the left lateral decubitus position, a flexible gastroscope (Olympus GIF-140 Video Gastrocope; Olympus Corp, Center Valley, Pa) was advanced and positioned in the esophagus just proximal to the anastomosis (Figure 1, B). An 18-gauge angiocatheter was introduced into the esophagus distal to the gastroscope and just proximal to the anastomosis. A pressure probe (FISO FOP $62.5 \mathrm{mi}-$ crons; FISO Technologies Inc, Quebec, Canada) was inserted through the angiocatheter into the anastomotic lumen (Figure 1, $A$ ). The pressure probe was zeroed to atmospheric pressure and intraluminal pressure measurement was begun. Gentle air insufflation was then supplied by the endoscope until the anastomosis was visualized clearly (Figure 2, A). Insufflation then continued until the intraluminal pressure reached a plateau and began to decrease as air leaked retrograde through the pig's mouth. The endoscope was passed through the anastomosis and conduit at maximal insufflation. The right gastroepiploic pulse was palpated intermittently as insufflation was administered progressively. The integrity of the anastomosis was verified before and after insufflation by submerging the anastomotic segment in a water bath and looking for the leakage of air bubbles from the staple lines, which has proven to be the most sensitive means of detecting a perforation in our previous studies. ${ }^{12}$

\section{Flow and Perfusion Studies}

Significant distension of the gastric conduit was observed with maximal endoscopic insufflation, and we next sought to examine the potential threat posed by conduit distension. In a separate series of experiments, 5 new pigs were anesthetized and a laparotomy performed according to our previously described protocol. Central and arterial lines were placed in the femoral vessels. Before manipulation of the stomach, a pulse oximeter was placed on the greater curvature, lesser curvature, fundus, and pylorus, and measurements were taken (Figure 2, B). When pulse oximeter measurements were variable, they were repeated until 2 to 3 measurements in the same region were consistent, and when the measured heart rate was similar to that measured by the intraoperative electrocardiogram.

The right gastroepiploic artery was then isolated along the greater curvature. We inserted a flow probe (Transonic 400; Transonic, Ithaca, NY) onto the right gastroepiploic artery for measurement of blood flow. The gastroscope was then advanced into the stomach and the stomach insufflated maximally until retrograde air leakage through the mouth was identified as described previously. Within 3 minutes of insufflation, pulse oximetry and gastroepiploic flow measurements were taken. These measurements were repeated at 10 minutes of maximal insufflation. The stomach was then deflated with the gastroscope and the scope was withdrawn. A set of pulse oximetry and flow measurements was taken about 2 to 3 minutes after deflation. These flow and pulse oximetry measurements before esophagectomy served as internal controls for the experimental conditions after esophagectomy.

An esophagectomy was then performed as described previously. Pulse oximetry and flow measurements were recorded 2 to 3 minutes after the

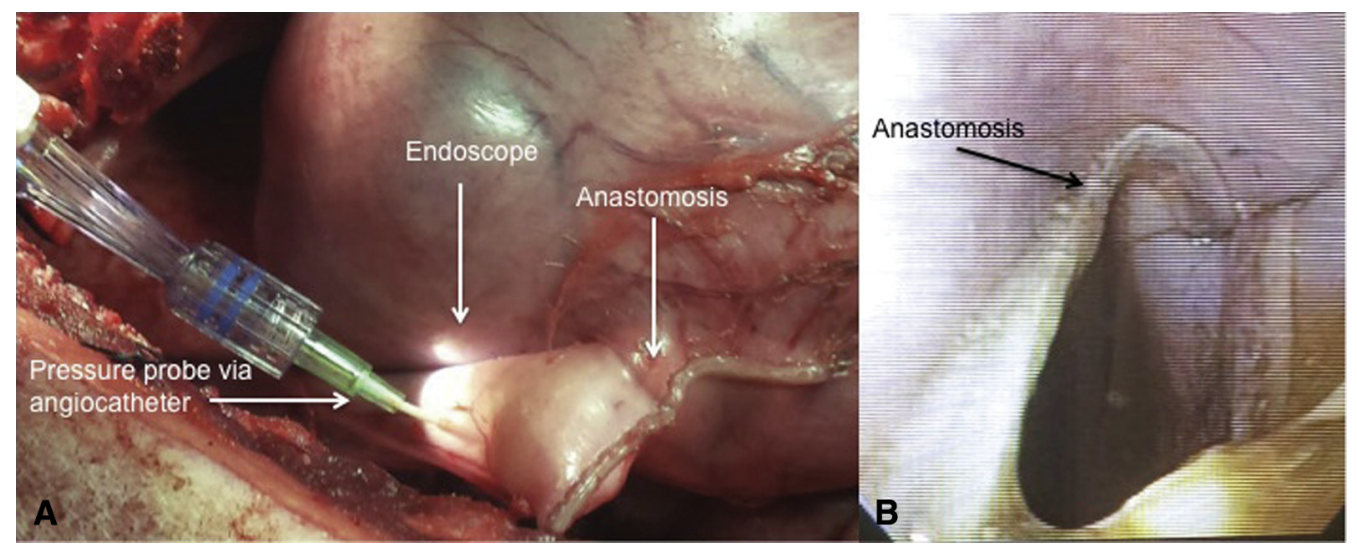

FIGURE 1. Photographs demonstrating (A) the position of endoscope and pressure probe near the gastroesophageal anastomosis and (B) the anastomosis visualized by the endoscope. 


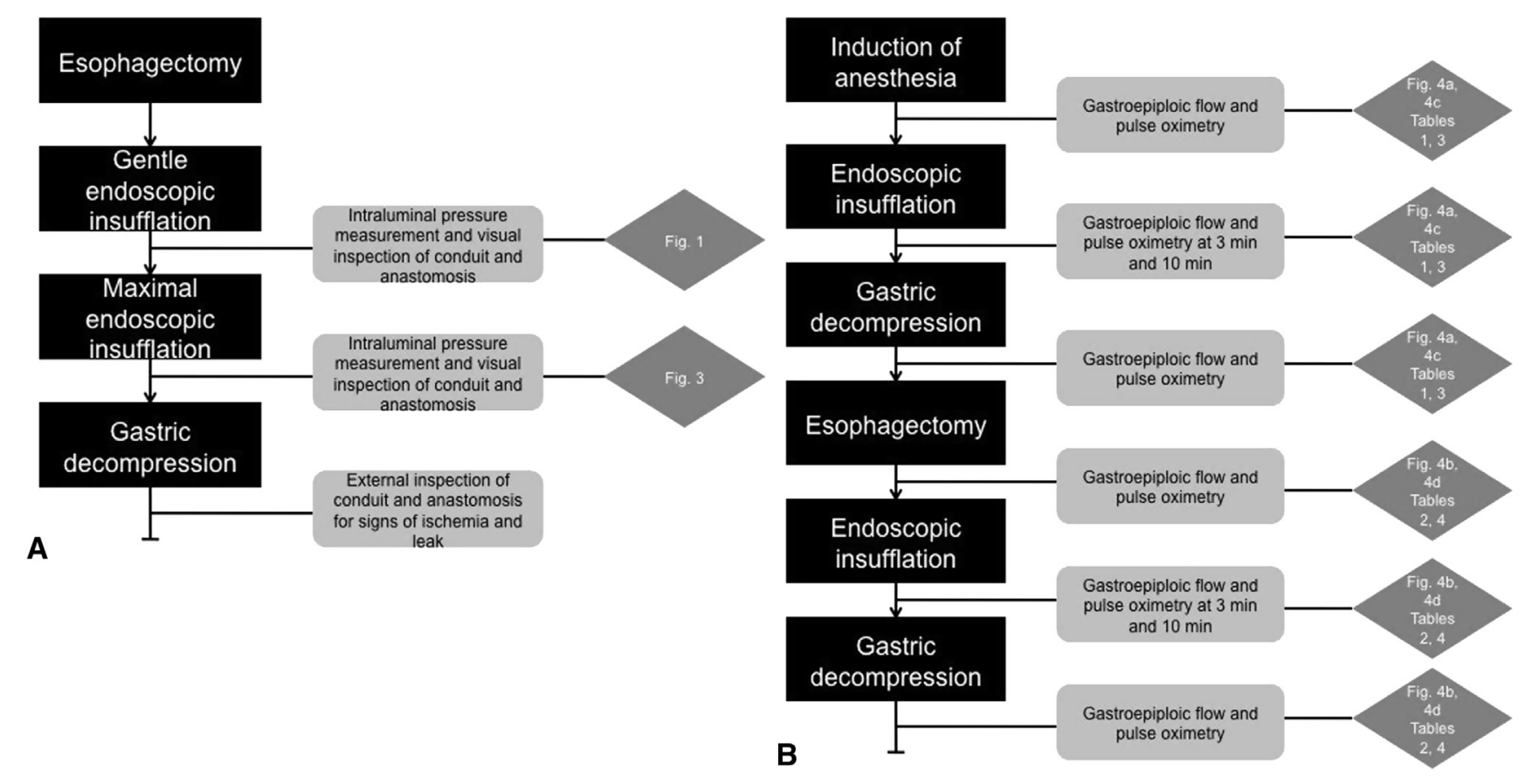

FIGURE 2. A and B, Flowcharts illustrating the order of experiments and measurements with corresponding table and figure numbers.

anastomosis was created. The gastroscope was once again advanced just proximally to the anastomosis and the gastric conduit insufflated maximally until retrograde air leakage. Pulse oximetry and right gastroepiploic flow were recorded within 3 minutes of maximal insufflation and again after 10 minutes of maximal insufflation. The stomach was then deflated and the scope withdrawn and a final set of pulse oximetry and flow measurements taken 2 to 3 minutes after deflation of the stomach. Throughout these experiments, the mean arterial pressure of the pig was maintained around $60 \mathrm{~mm} \mathrm{Hg}$, and temperature of the pig was maintained around $37^{\circ} \mathrm{C}$. Crystalloids, rather than pressors, were used to maintain the pigs' mean arterial pressure, given the theoretical risk of ischemia to the conduit from vasoconstriction and confounding of the study.

\section{Statistical Analysis}

All data are reported as a mean with $95 \%$ confidence interval and error bars as standard error of the mean unless otherwise noted. Statistical analysis was performed with GraphPad Prism, version 6.00 (GraphPad Software Inc, La Jolla, Calif).

\section{RESULTS}

\section{Intraluminal Pressure With Endoscopic Insufflation After Esophagectomy}

With endoscopic air insufflation of the gastroesophageal anastomosis, there was safe passage of the endoscope through the anastomosis and conduit without any overt, visible disruption to the anastomotic or conduit staple lines or gastric mucosa. With progressive insufflation, intraluminal pressure increased to a maximum of $8.73 \pm 2.12 \mathrm{~cm} \mathrm{H}_{2} \mathrm{O}(95 \%$ confidence interval, 7.2110.24) (Figure $3, B$ ). The intraluminal pressure reached a plateau at this recorded maximum where gastric distension had maximized and air began to leak retrograde through the pig's mouth, which was noted by an audible hissing. With gentle air insufflation, minimal distension of the gastric conduit was observed; however, with maximal insufflation, significant gastric distension occurred (Figure 3, A). The stomach remained pink, however, with a palpable gastroepiploic pulse in all experiments. In addition, there were no signs of ischemia on endoscopy after maximal insufflation. The gastroesophgeal anastomosis, the gastric conduit staple line, the stomach, and the esophagus were free of perforation at all stages of the 10 experiments.

\section{Flow and Perfusion of Gastric Conduit With \\ Endoscopic Insufflation After Esophagectomy}

In the next part of the study, we examined the risk to the anastomosis and conduit posed by gastric distension observed with maximal endoscopic insufflation. Pulse oximetry revealed hemoglobin oxygen saturation greater than or equal to $95 \%$ along the greater curvature, fundus, lesser curvature, and pylorus of the stomach before endoscopy, within 3 minutes of maximal endoscopic insufflation and gastric distension, with sustained insufflation and distension at 10 minutes and after gastric decompression (Figure 4, $A$ and Table 1). After esophagectomy, mean oxyhemoglobin saturation decreased (Figure $4, B$ and Table 2). There was no significant change in saturation with 10 minutes of maximal insufflation after esophagectomy (Table 2). After gastric decompression and scope 

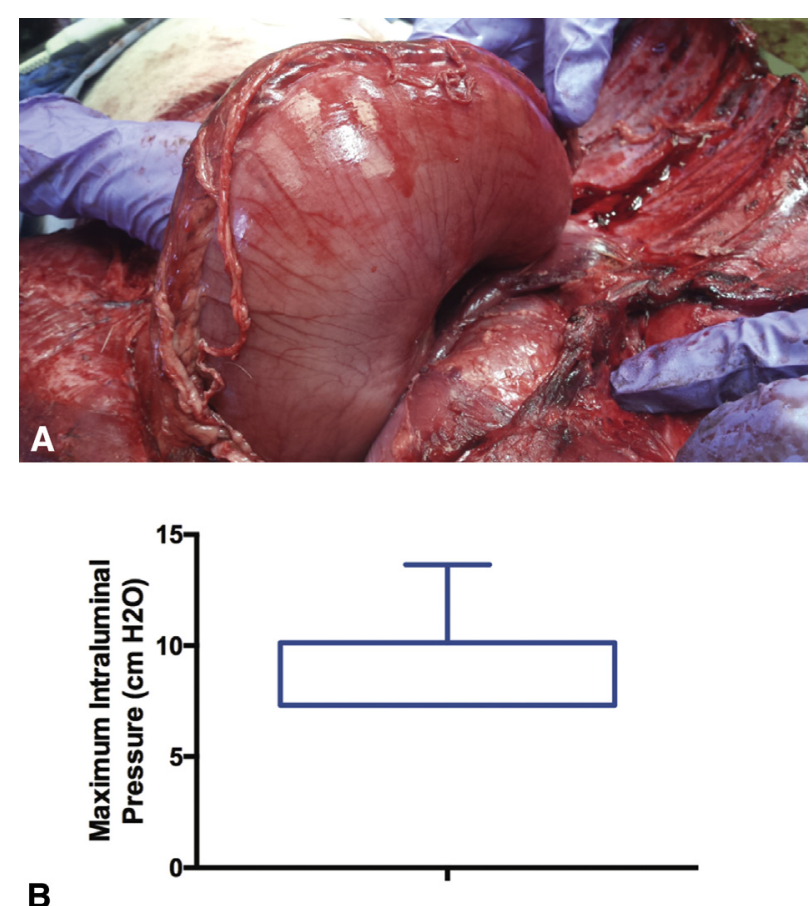

FIGURE 3. Photographs showing (A) maximally distended stomach conduit with endoscopic air insufflation and (B) box-and-whisker plot demonstrating the maximum intraluminal pressure achieved with progressive insufflation.

withdrawal, the saturations remained the same (Table 2). The oxyhemoglobin saturations along the fundus of the conduit were significantly lower throughout $(P=.04)$ than those along the greater curvature.

Before esophagectomy, Doppler velocimetry measurements of the right gastroepiploic artery decreased $(P=.01) 3$ minutes after maximal endoscopic insufflation but recovered with 10 minutes of insufflation and remained constant with complete decompression (Figure 4, $C$ and Table 3). After esophagectomy and with 3 minutes of maximal insufflation, right gastroepiploic flow once again decreased $(P=.02)$ compared with flow before endoscopic insufflation but again recovered with 10 minutes of insufflation and subsequent decompression (Figure 4, $D$ and Table 4). There were no other significant differences in flow. Throughout these experiments, the gastric conduit appeared pink, the mucosa pink and healthy, and there was a palpable gastroepiploic pulse.

\section{DISCUSSION}

Anastomotic leaks and gastric conduit ischemia cause significant morbidity after esophagectomy. Endoscopy is gaining favor as the test of choice in evaluating conduits after esophagectomy as the result of its many advantages. However, clinicians hesitate to use endoscopy after esophagectomy because (1) the endoscope could mechanically disrupt the anastomosis, (2) insufflation pressure during endoscopy could perforate the anastomosis, and (3) insufflation can cause gastric conduit distension, compromising blood flow. Previous retrospective clinical studies have reported the safe use of endoscopy with "gentle insufflation" after esophagectomy. ${ }^{5,6}$ In the largest retrospective study of postesophagectomy endoscopy within 21 days postoperatively, 102 patients had no complications attributable to endoscopy. ${ }^{3}$ Nevertheless, there has been no previous animal model or clinical trial to determine the safe parameters of insufflation for postesophagectomy endoscopy.

In this study, we used an in vivo pig model to evaluate the safety of endoscopy immediately after esophagectomy. We sought to investigate whether endoscopy itself would mechanically disrupt staple lines. In 15 models, including the 10 animals in the manometry studies and the 5 animals in the flow and oximetry studies, we found that endoscopy could be conducted with sufficient precision as to avoid mechanically disrupting staples lines, including an anastomosis. In experienced hands, maneuvering the endoscope within the esophagus, the anastomosis, and the gastric conduit appears to impart little risk of injury. Second, we examined the risk of insufflation and intraluminal pressure to staple lines after esophagectomy. We found that intraluminal pressures from endoscopy, with standard air insufflation to maneuver the endoscope safely, did not injure or perforate any staple line, most notably the gastroesophgeal anastomosis. Moreover, even with maximum insufflation, the intraluminal pressure measured at the anastomosis never increased beyond a mean of $9 \mathrm{~cm} \mathrm{H}_{2} \mathrm{O}$. With excessive insufflation, intraluminal pressure did not increase beyond this plateau pressure because the gastric conduit was freely distensible and air leaked through the oropharynx. Our previous work demonstrated that an intraluminal pressure of $84 \pm 38 \mathrm{~cm} \mathrm{H}_{2} \mathrm{O}$ is needed to disrupt an in vivo esophagogastric anastomosis. ${ }^{12}$ It is therefore likely that air insufflation, even when used generously, cannot mount pressures that could conceivably disrupt an esophagectomy anastomosis.

In the second part of our study, we examined the threat posed to a gastric conduit and gastroesophageal anastomosis with air insufflation. Increased intraluminal pressures of the gastric conduit may cause extrinsic compression of the gastric vessels, reduced blood flow, and compromised perfusion. We used parenchymal oxyhemoglobin saturation as a measure of gastric perfusion and found that endoscopic insufflation, both before and after esophagectomy, does not significantly reduce tissue oxygenation even after 10 minutes of sustained maximal distension. Furthermore, both the stomach serosa and mucosa appeared pink and well-perfused throughout the 10 minutes of insufflation, assuring us of good gastric 

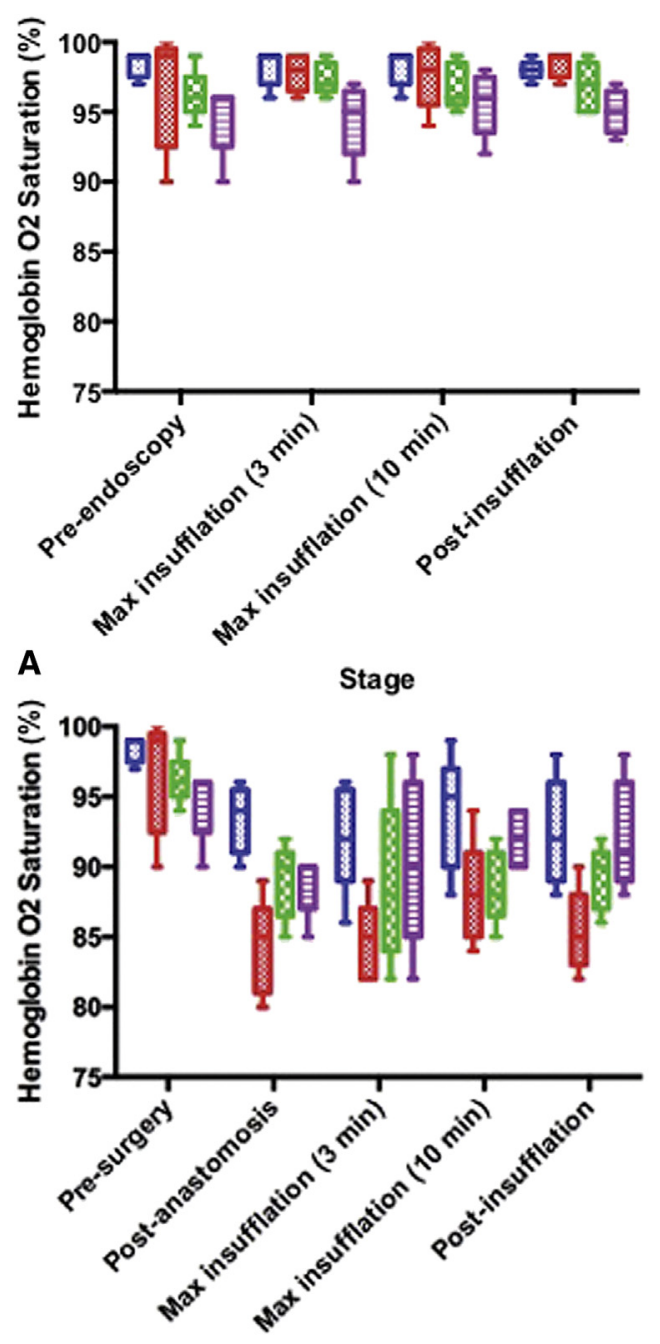

B

Stage

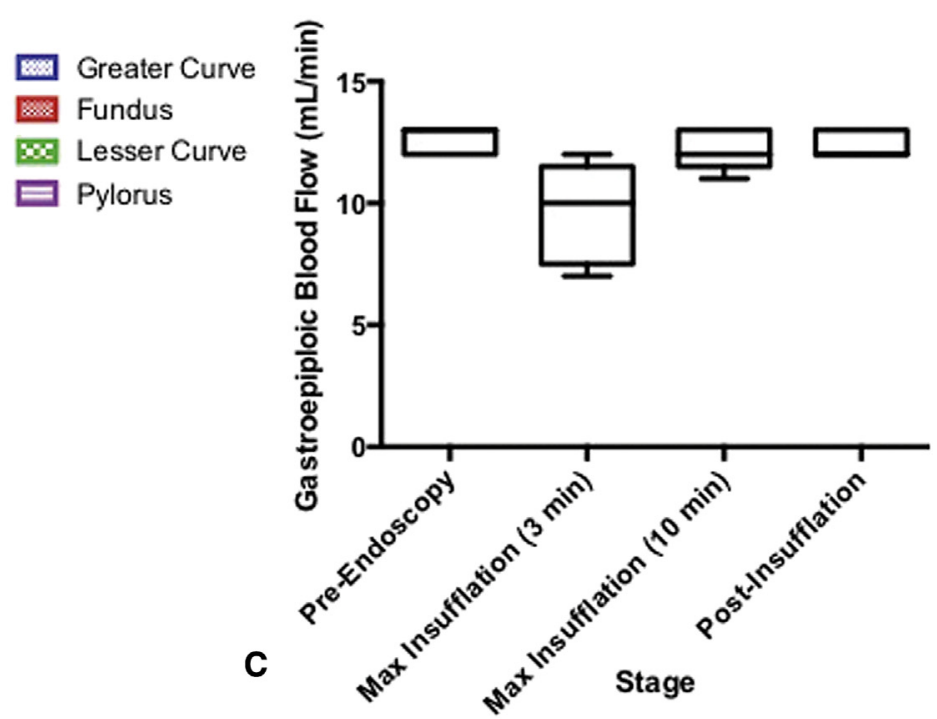

Greater Curve
Fundus
$\otimes$ Lesser Curve
$\equiv$ Pylorus

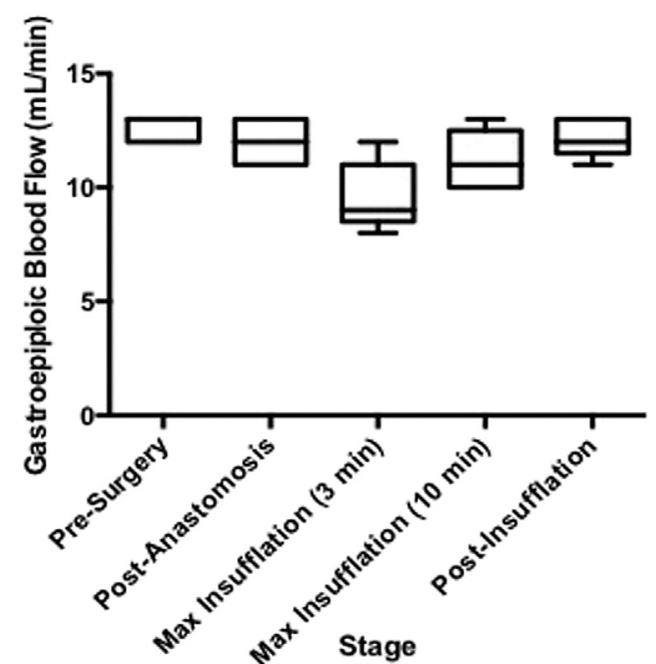

FIGURE 4. Box-and-whisker plots demonstrating (A) oxyhemoglobin saturation at 4 different regions in the stomach with endoscopy before esophagectomy, (B) oxyhemoglobin saturation at 4 different regions in the stomach with endoscopy after esophagectomy, (C) right gastroepiploic arterial flow with endoscopy before esophagectomy, and (D) right gastroepiploic arterial flow with endoscopy after esophagectomy.

perfusion. We did find that saturations in the fundal portion of the gastric conduit were consistently and significantly lower than along the greater curvature both with and without insufflation. This finding is not surprising, given the loss of supply to the fundus by ligation of the left gastric artery and short gastric arteries during esophagectomy. Previous studies have measured a loss of blood flow to the fundus by a mean of $55 \% \cdot{ }^{15-17}$ Despite the relatively lower oxygen saturation of the fundus compared with other portions of the gastric conduit, the fundal perfusion appeared adequate, with endoscopic insufflation in our experiments with saturations greater than $85 \%$ and no gross or endoscopic suggestion of ischemia.

TABLE 1. Oxyhemoglobin saturation before esophagectomy

\begin{tabular}{lcccr}
\hline \multicolumn{1}{c}{ Measurement point } & $\begin{array}{c}\text { Oxyhemoglobin } \\
\text { saturation in } \\
\text { fundus, \% }\end{array}$ & $\begin{array}{c}\text { Oxyhemoglobin } \\
\text { saturation in } \\
\text { greater curve, \% }\end{array}$ & $\begin{array}{c}\text { Oxyhemoglobin } \\
\text { saturation in lesser } \\
\text { curve, \% }\end{array}$ & $\begin{array}{c}\text { Oxyhemoglobin } \\
\text { saturation in pylorus, \% }\end{array}$ \\
\hline Before endoscopy & $96.6 \pm 4.16$ & $98.4 \pm 0.89$ & $96.2 \pm 1.79$ & $94.6 \pm 2.61$ \\
Maximum insufflations, 3 min & $97.8 \pm 1.30$ & $98.2 \pm 1.30$ & $97.4 \pm 1.14$ & $94.4 \pm 2.70$ \\
Maximum insufflations, 10 min & $97.6 \pm 2.30$ & $98.2 \pm 1.30$ & $96.8 \pm 1.64$ & $95.6 \pm 2.30$ \\
After decompression & $98.4 \pm 0.89$ & $98.0 \pm 0.71$ & $96.8 \pm 1.79$ & $95.0 \pm 1.58$ \\
\hline
\end{tabular}


TABLE 2. Oxyhemoglobin saturation after esophagectomy

\begin{tabular}{lccrr}
\hline \multicolumn{1}{c}{ Measurement point } & $\begin{array}{c}\text { Oxyhemoglobin saturation } \\
\text { in fundus, \% }\end{array}$ & $\begin{array}{c}\text { Oxyhemoglobin } \\
\text { saturation in } \\
\text { greater curve, \% }\end{array}$ & $\begin{array}{c}\text { Oxyhemoglobin } \\
\text { saturation in } \\
\text { lesser curve, \% }\end{array}$ & $\begin{array}{c}\text { Oxyhemoglobin } \\
\text { saturation in pylorus, \% }\end{array}$ \\
\hline Before surgery & $96.6 \pm 4.2$ & $98.4 \pm 0.89$ & $96.2 \pm 1.8$ & $94.6 \pm 2.6$ \\
After esophagectomy & $84 \pm 3.4$ & $93 \pm 2.4$ & $89 \pm 2.6$ & $89 \pm 2.2$ \\
Maximum insufflations, 3 min & $85 \pm 2.9$ & $92 \pm 3.9$ & $89 \pm 5.9$ & $90 \pm 6.1$ \\
Maximum insufflations, 10 min & $88 \pm 3.7$ & $94 \pm 4.1$ & $89 \pm 2.6$ & $92 \pm 2.0$ \\
After decompression & $85 \pm 3.0$ & $92 \pm 3.8$ & $89 \pm 2.3$ & $92 \pm 3.9$ \\
\hline
\end{tabular}

To further characterize ischemic potential during endoscopic insufflation, we measured flow in the right gastroepiploic artery before, during, and after endoscopic insufflation. We repeated endoscopic insufflation measurements in the setting of esophagectomy. We found a significant reduction in flow immediately after gastric insufflation with recovery to preinsufflation values as insufflation continued. This trend was observed with and without esophagectomy. A possible explanation is extrinsic compression of the gastroepiploic artery with insufflation and gastric distension followed by progressive decompression with movement of the stomach and arteries, resulting in recovered flow. Even with diminished flow immediately on insufflation, gastric perfusion as measured by oxyhemoglobin saturation and observed by gross and endoscopic visualization of the conduit remained adequate. Autoregulatory mechanisms may alter resistance in vessels downstream from the gastroepiploic artery to compensate for lower blood flow to keep oxyhemoglobin saturation stable. This phenomenon, however, deserves further study. It is likely that significant and sustained gastric distension does not pose a great threat to the anastomosis or conduit after esophagectomy, which is an important lesson not only for endoscopic insufflation but also gastric distension due to other reasons like food or positive pressure ventilation. ${ }^{12}$

Our in vivo pig model has been used successfully to measure intraluminal pressure, tissue perfusion, regional blood flow, and anstomotic leak. In this study, we examined the effects of endoscopy on a gastroesophageal anastomosis. Future directions include quantifying the effect of endoscopy in the setting of known esophageal perforation.

TABLE 3. Gastroepiploic flow before esophagectomy

\begin{tabular}{lcc}
\hline \multicolumn{1}{c}{ Measurement point } & $\begin{array}{c}\text { Median } \\
\text { gastroepiploic } \\
\text { flow, } \\
\text { mL/min/100 g }\end{array}$ & $\begin{array}{c}\text { Mean } \\
\text { gastroepiploic } \\
\text { flow, } \\
\text { mL/min/100 g }\end{array}$ \\
\hline Before endoscopy & 13 & $12.6 \pm 0.55$ \\
Maximum insufflations, 3 min & 10 & $9.60 \pm 2.1$ \\
Maximum insufflations, 10 min & 12 & $12.2 \pm 0.84$ \\
After decompression & 12 & $12.4 \pm 0.55$ \\
\hline
\end{tabular}

There are several important limitations to our study. First, we used a porcine model that cannot be generalized to human patients. Second, our study, especially for flow and perfusion measurements, is limited by a small number of experiments. However, our use of an internal control setup with the nonesophagectomy measurements improves the internal validity of our data. Third, we performed endoscopy on healthy anastomoses and conduits. In the setting of a leak, tissue may be infected, inflamed, ischemic, or necrotic. These tissues do not have the tensile strength of normal tissue and may perforate more readily. Even though we understand that a normal anastomosis can handle more than 3 times the amount of pressure that endoscopy imparts, we advise particular caution in the setting of a suspected leak. We emphasize, however, that our experimental conditions imparted more stress to the anastomosis than most clinical situations. Although clinicians generally use just enough insufflation to inspect the conduit and anastomosis, we provided maximum insufflation for several minutes to the point of vigorous retrograde air leakage through the mouth.

Fourth, our studies were all performed with a linear stapled side-to-side functional end-to-end anastomosis, and our findings cannot be generalized to other anastomotic techniques, although the leak rates of stapled techniques have been shown to be similar, and the linear stapled technique is the most popular nowadays. ${ }^{14}$ Fifth, we performed intrathoracic anastomoses in all our pigs, and our results therefore cannot be extrapolated to cervical anastomoses. Sixth, we performed endoscopy immediately after esophagectomy. Inflammation of the anastomosis and conduit would peak several days after surgery when a leak is also most likely. Again, our study likely overestimates the tensile strength of such inflamed tissue in a clinical setting.

Seventh, we did not address the question of harm to a disrupted anastomosis. There is concern that endoscopy could widen a preexisting anastomotic perforation. ${ }^{5,10}$ In addition, a leak could provide passage of additional air and luminal contents in the setting of endoscopy. Although our study did not specifically examine the mechanical threat posed to an already-leaking anastomosis by endoscopy, previous retrospective clinical studies in patients have demonstrated safety in this setting. ${ }^{3-5}$ Eighth, our observation of 
TABLE 4. Gastroepiploic flow after esophagectomy

\begin{tabular}{|c|c|c|}
\hline Measurement point & $\begin{array}{c}\text { Median } \\
\text { gastroepiploic } \\
\text { flow, } \\
\mathrm{mL} / \mathrm{min} / \mathbf{1 0 0} \mathrm{g}\end{array}$ & $\begin{array}{c}\text { Mean } \\
\text { gastroepiploic } \\
\text { flow, } \\
\mathrm{mL} / \mathrm{min} / \mathbf{1 0 0} \mathrm{g}\end{array}$ \\
\hline Before surgery & 13 & $12.6 \pm 0.55$ \\
\hline After esophagectomy & 12 & $12.0 \pm 1.0$ \\
\hline Maximum insufflations, $3 \mathrm{~min}$ & 9 & $9.6 \pm 1.5$ \\
\hline Maximum insufflations, $10 \mathrm{~min}$ & 11 & $11.2 \pm 1.3$ \\
\hline After decompression & 12 & $12.2 \pm 0.84$ \\
\hline
\end{tabular}

endoscopy through a thoracotomy does not recreate the clinical scenario of a closed chest. As noted in previous studies, however, our experimental model does not impart as much surrounding structure as the in vivo chest and is, in fact, more likely to cause distension, decreased flow, and ischemia than the in vivo setting. ${ }^{12,18}$

\section{CONCLUSIONS}

We demonstrate in an in vivo porcine model that endoscopy with sustained maximum insufflation does not mechanically disrupt a gastroesophageal anastomosis, imparts minimal intraluminal pressure to the anastomosis, and results in minimum disturbances to blood flow and tissue oxygenation of the conduit. Our work provides a platform for future translational and clinical investigations into the safety of endoscopy after esophagectomy.

\section{Conflict of Interest Statement}

Authors have nothing to disclose with regard to commercial support.

We are grateful to Susan Kane, CVT, for assistance in pig surgery and Tyler Kempf from DRE Medical Equipment for endoscope rental. We were supported by a Dartmouth SYNERGY grant.

\section{References}

1. Briel JW, Tamhankar AP, Hagen JA, DeMeester SR, Johansson J, Choustoulakis E, et al. Prevalence and risk factors for ischemia, leak, and stricture of esophageal anastomosis: gastric pull-up versus colon interposition1. J Am Coll Surg. 2004;198:536-41.
2. Cools-Lartigue J, Andalib A, Abo-Alsaud A, Gowing S, Nguyen M, Mulder D, et al. Routine contrast esophagram has minimal impact on the postoperative management of patients undergoing esophagectomy for esophageal cancer. Ann Surg Oncol. 2014;21:2573-9.

3. Maish MS, DeMeester SR, Choustoulakis E, Briel JW, Hagen JA, Peters JH, et al. The safety and usefulness of endoscopy for evaluation of the graft and anastomosis early after esophagectomy and reconstruction. Surg Endosc. 2005;19: 1093-102.

4. Page RD, Asmat A, McShane J, Russell GN, Pennefather SH. Routine endoscopy to detect anastomotic leakage after esophagectomy. Ann Thorac Surg. 2013;95: 292-8.

5. Griffin SM, Shaw IH, Dresner SM. Early complications after Ivor Lewis subtotal esophagectomy with two-field lymphadenectomy: risk factors and management. J Am Coll Surg. 2002;194:285-97.

6. Trentino P, Pompeo E, Nofroni I, Francioni F, Rapacchietta S, Silvestri F, et al. Predictive value of early postoperative esophagoscopy for occurrence of benign stenosis after cervical esophagogastrostomy. Endoscopy. 1997;29:840-4.

7. Mardin WA, Palmes D, Bruewer M. Current concepts in the management of leakages after esophagectomy. Thorac Cancer. 2012;3:117-24.

8. Pross M, Manger T, Reinheckel T, Mirow L, Kunz D, Lippert H. Endoscopic treatment of clinically symptomatic leaks of thoracic esophageal anastomoses. Gastrointest Endosc. 2000;51:73-6.

9. Schubert D, Scheidbach H, Kuhn R, Wex C, Weiss G, Eder F, et al. Endoscopic treatment of thoracic esophageal anastomotic leaks by using silicone-covered, self-expanding polyester stents. Gastrointest Endosc. 2005;61:891-6.

10. Crestanello JA, Deschamps C, Cassivi SD, Nichols FC, Allen MS, Schleck C, et al. Selective management of intrathoracic anastomotic leak after esophagectomy. J Thorac Cardiovasc Surg. 2005;129:254-60.

11. Low DE. Diagnosis and management of anastomotic leaks after esophagectomy. J Gastrointest Surg Off J Soc Surg Aliment Tract. 2011;15: 1319-22.

12. Raman V, MacGlaflin CE, Erkmen CP. Non-invasive positive pressure ventilation following esophagectomy: safety demonstrated in a pig model. Chest. 2015;147: 356-61.

13. Raman V, Kaiser LR, Erkmen CP. Clinical pathway for esophagectomy improves perioperative nutrition. Healthc (Amst). 2016;4:166-72.

14. Price TN, Nichols FC, Harmsen WS, Allen MS, Cassivi SD, Wigle DA, et al. A comprehensive review of anastomotic technique in 432 esophagectomies. Ann Thorac Surg. 2013;95:1154-60; discussion 1160-1.

15. Schröder W, Beckurts KTE, Stähler D, Stützer H, Fischer JH, Hölscher AH. Microcirculatory changes associated with gastric tube formation in the pig. Eur Surg Res Eur Chir Forsch Rech Chir Eur. 2002;34:411-7.

16. Boyle NH, Pearce A, Hunter D, Owen WJ, Mason RC. Scanning laser Doppler flowmetry and intraluminal recirculating gas tonometry in the assessment of gastric and jejunal perfusion during oesophageal resection. Br J Surg. 1998;85: 1407-11.

17. Hölscher AH, Schneider PM, Gutschow C, Schröder W. Laparoscopic ischemic conditioning of the stomach for esophageal replacement. Ann Surg. 2007;245: 241-6.

18. Erkmen CP, Raman V. Response. Chest. 2016;149:602-3.

Key Words: endoscopy, esophagectomy, anastomosis, leak, insufflation, pressure, ischemia 